\title{
EDUCAÇÃO SEM FILOSOFAR UMA NÃO-IMPOSSIBILIDADE QUE INTERESSA A QUEM ?*
}

\author{
Wanderlei da Silva de Oliveira**** \\ Diretoria de Ensino (DERSA) - Santo André - São Paulo
}

\begin{abstract}
RESUMO
Este artigo tem como objeto de reflexão o tema da II Semana de Filosofia da Metodista: "Filosofia e Educação: é possível educação sem filosofar?". Seu objetivo principal é apresentar alguns pressupostos que poderiam sustentar ao menos duas respostas possíveis à questão presente no tema: uma negativa e outra afirmativa. Por meio de uma revisão bibliográfica, analisaremos os três principais termos que compõem o tema: a) "possível”, a partir do seu significado nominal e suas definições conceituais, priorizando a que o compreende como não-impossível; b) "educação", apontando não apenas noções amplas, que fundamentam sistemas e modelos educacionais, mas também antagônicas, que permeiam o universo escolar; c) e "filosofar", entendido como incômoda e profícua atividade intelectual inerente a uma educação emancipadora.
\end{abstract}

Palavras-chave: Filosofia. Educação. Reflexão crítica. Possível. Filosofar.

* Trabalho apresentado ao eixo temático "Filosofia e Educação: é possível educação sem filosofar?"daII Semana de Filosofia da Metodista. São Bernardo do Campo, SP, 14-17 out. 2019.

** Especialista em Filosofia e Ensino de Filosofia pelo Centro Universitário Claretiano (CEUCLAR). Licenciado em Filosofia pelo Centro Universitário Assunção (UNIFAI). Licenciado em Pedagogia pela Universidade de Taubaté (UNITAU). Bacharel em Teologia pela Pontifícia Faculdade de Teologia Nossa Senhora da Assunção (UNIFAI e PUC). Professor Coordenador de Núcleo Pedagógico da Diretoria de Ensino Região de Santo André. Docente de Filosofia da Escola Estadual "Dr. Américo Brasiliense". E-mail: wanderlei.oliveira@educacao.sp.gov.br 


\section{INTRODUÇÃo}

Repensar a questão "é possível educação sem filosofar?"implica em refletir sobre um problema legitimamente filosófico. Considerando o atual contexto em que determinados grupos políticos e representantes da sociedade civil atribuem a algumas correntes de pensamento o caráter pretensamente doutrinador e a manifestações públicas de adolescentes e jovens contra medidas governamentais a suposta manipulação de professores, em sua grande maioria, da área de Ciências Humanas, é importante repensar criticamente a formação do sujeito contemporâneo.

Uma alternativa viável para refletir sobre o tema da II Semana de Filosofia da Metodista é analisar os 3 principais conceitos que compõem a questão supracitada: possível, educação e filosofar. Iniciaremos a investigação tratando a educação escolar como fonte de estímulo ao uso crítico da razão, seja ou não a filosofia um componente obrigatório no currículo. Em seguida analisaremos o termo possível a partir de seu significado nominal e algumas de suas definições conceituais que perpassam a História da Filosofia. Logo após apresentaremos a noção ampla de educação explícita na legislação federal e nas ideias de Dewey e Furter. Por último, com base no pensamento de Lipman e Lorieri, abordaremos a importância de promover o desenvolvimento do pensar filosófico em crianças e jovens durante a educação básica. Com isso esperamos obter subsídios para responder à questão proposta como tema da II SEFIME.

\section{A EduCAÇão escolar e o estímulo ao USO CRÍTICO DO "SEPARADOR DE ORELHAS"}

De modo geral, a prática docente baseia-se em duas concepções antagônicas de educação: uma que procura conservar e reproduzir a sociedade vigente, com todas as suas contradições e desigualdades, e outra que busca transformar a realidade por meio do desenvolvimento da autonomia, do senso crítico e de valores e competências fundamentais para a construção de uma sociedade com reais opor- 
tunidades de crescimento para todos os seres humanos. Apesar do evidente antagonismo entre as duas concepções, não é raro encontrar seus elementos característicos mesclados na prática pedagógica de um mesmo professor.

Nos casos em que os docentes não apresentam uma visão clara sobre a importância e o papel da educação escolar no meio social, sua prática pode ser norteada, parcial ou integralmente, pelos princípios que fundamentam os currículos oficiais dos sistemas de ensino nos quais estão inseridos. Todavia, esses currículos já são a expressão pedagógica de um modelo teórico de homem, de sociedade, de mundo e, consequentemente, de educação. Ainda que o professor seja indiferente a esse fato, sua prática sempre estará a serviço de um determinado modelo educacional. De qualquer forma, independentemente da área do conhecimento, uma distinção básica entre um professor e outro está no nível de criticidade com que implementam o currículo estabelecido e no modo como propiciam ou não o desenvolvimento do senso crítico do aluno em relação ao próprio processo de aprendizagem.

Uma escola técnica estadual na década de 90, por exemplo, antes mesmo da promulgação da LDB (e, obviamente, antes da Lei no 11684 , de 2008), não tinha a obrigação de garantir aos seus alunos o ensino de Filosofia e Sociologia. Por outro lado, a formação de técnicos, como qualquer outra modalidade de educação, deveria visar tanto à qualificação para o trabalho quanto à preparação para o exercício da cidadania e ao pleno desenvolvimento da pessoa (Art. 205, CF 88). Sendo assim, não podemos considerar a criticidade uma dimensão exclusiva de apenas alguns componentes curriculares ou somente uma área do conhecimento. Por isso, não é estranho que um professor de Física de uma escola técnica do período supracitado tenha estimulado em seus alunos o uso crítico de um dispositivo que ele chamava de "separador de orelhas".

Além do fato de manter uma orelha separada da outra (e oferecer suporte para vastas cabeleiras, bonés, chapéus...) esse dispositivo natural, localizado acima do pescoço, possui funções internas que às vezes são esquecidas ou subutilizadas pelos seres humanos. Duas dessas funções são exercidas pela faculdade da razão: pensamento crítico e reflexão ética. Tais atividades do intelecto exigem, obviamente, um uso 
muito mais apurado do nosso "separador de orelhas" do que a ação de escolher entre um corte de cabelo e outro. Portanto, o que se pode esperar de uma educação escolar é, no mínimo, a oferta de oportunidades e situações de aprendizagem diversas que estimulem o desenvolvimento dessas funções mais elevadas da inteligência humana. E se a reflexão crítica é inerente à atividade filosófica, é justificável a empreitada de investigar se é possível ou não uma educação sem filosofar.

\section{O TERMO "POSSÍVEL"}

Para repensar a questão tema da SEFIME, optamos pela análise dos três principais termos que a compõem. 0 primeiro deles é "possível”, cujas definições conceituais expressam problemas peculiares que perpassam os grandes períodos da História da Filosofia. No aspecto nominal, refere-se àquilo que pode ser ou não ser. No aspecto conceitual, temos as definições negativas e positivas. As primeiras, de natureza lógica, definem o possível "como aquilo que não é necessariamente falso ou não inclui contradição” (ABBAGNANO, 2007, p. 789). As últimas podem ser de possibilidade real ou de possibilidade objetiva. Em relação a esta noção, uma de suas teses fundamentais refere-se à redução do possível "ao não-impossível"; e outra infere o possível "a partir do necessário, no sentido de que o necessário deve ser possível”, pois se não o fosse, seria impossível, o que, logicamente, é contraditório (Ibid.).

Em educação, há uma série de exemplos em que essas definições estão presentes. Vejamos o caso da Deliberação CEE no 9/1997, que instituiu, no Sistema de Ensino do Estado de São Paulo, o regime de progressão continuada no ensino fundamental. Teoricamente, a reorganização da segunda etapa da educação básica deveria diminuir drasticamente os índices de reprovação e evasão escolar e, ao mesmo tempo, garantir um período maior de aprendizagem para que todos os alunos pudessem desenvolver habilidades, competências e conhecimentos de acordo com as metas estipuladas para os seus respectivos segmentos. Se é verdade que os alunos aprendem em ritmos e tempos diferentes, considerando o ideal de uma educação plenamente inclusiva, então 
esse regime, além de não-contraditório, é também não-impossível. $\mathrm{Na}$ prática, porém, pela falta de estrutura e formação adequadas ou pela simples resistência de boa parte dos docentes, o regime de progressão continuada ficou conhecido como "sistema de promoção automática", marcado pela chegada de um percentual de alunos ao ensino médio com grande defasagem em leitura, escrita e cálculo.

Como vemos, algo considerado necessário, imprescindível e, em condições ideais, perfeitamente possível, torna-se, pela legislação, um dever assumido pelo poder público. 0 cumprimento desse dever, no choque entre o ideal/legal e o real, pela falta de determinadas condições objetivas e subjetivas para realizar-se, acaba sendo impossível em algumas situações. Será que o mesmo vale para o ato de filosofar? Tal atividade intelectual seria imprescindível ou dispensável à educação? Caso seja imprescindível, seria não-impossível que fosse dispensável? Ou isso seria totalmente contraditório?

\section{ConCEPÇÃo ABRAnGENTE de EDUCAÇÃo}

Uma noção ampla de educação está relacionada ou ao processo de educar(-se) ou a qualquer estágio desse processo. Podemos defini-la tanto como "aplicação dos métodos próprios para assegurar a formação e o desenvolvimento físico, intelectual e moral de um ser humano (pedagogia, ensino, didática)" quanto "conhecimento e desenvolvimento resultantes desse processo" (HOUAISS, 2004).

Para expor essa noção ampla do termo analisado, o artigo 1ㅇ da LDBEN afirma categoricamente que "a educação abrange os processos formativos que se desenvolvem na vida familiar, na convivência humana, no trabalho, nas instituições de ensino e pesquisa, nos movimentos sociais e organizações da sociedade civil e nas manifestações culturais".

Uma definição interessante é a que Anísio Teixeira nos apresenta no estudo preliminar dos ensaios pedagógicos A criança e o programa escolar e Interesse e esforço de Dewey: educação é "o processo de reconstrução e reorganização da experiência, pelo qual lhe percebemos mais agudamente o sentido, e com isso nos habilitamos a melhor dirigir 
o curso de nossas experiências futuras" (DEWEY, 1980, p. 116). Sob essa perspectiva não podemos separar vida, experiência e aprendizagem, pois vivemos, experimentamos e aprendemos simultaneamente. "A experiência educativa é, pois, essa experiência inteligente em que participa o pensamento, através do qual se vêm a perceber relação e continuidades antes não percebidas". Através dessa experiência, "o fim (o resultado) da educação se identifica com seus meios (o processo), do mesmo modo, aliás, que os fins da vida se identificam com o processo de viver" (Ibid.).

Outros estudiosos do assunto, partindo de pressupostos diferentes, também chegam à constatação de que há uma relação estreita entre educação e vida. Para o suíço Pierre Furter, por exemplo, "o homem, por ser inacabado, tende à perfeição. A educação é, portanto, um processo contínuo que só acaba com a morte" (FURTER, 1971, p. 67). É indispensável na vida de qualquer indivíduo, pois sem ela, "o filho do homem nunca chegará a ser realmente humano" (Ibid., p. 69). Na base de tal proposição está a ideia de que o homem nasce prematuro, e por isso precisa da educação, do cuidado dos pais e da sociedade para ter condições de aperfeiçoar seu desenvolvimento, seu progresso, sua evolução. Sem os meios que lhe proporcionem condições para esse aperfeiçoamento, nunca passará de um ser vivo qualquer. Depois de nascer, então, o homem continua "evoluindo lentamente, tão lentamente quanto necessário para poder aproveitar uma aprendizagem complexa e completa" (Ibid., p. 72).

Parte considerável da vida e do desenvolvimento cognitivo e socioemocional de um número cada vez maior de seres humanos ocorre em instituições escolares. Embora cientes de que "a escola não pode mais ser concebida como o único foco possível de ação educativa das transformações sociais e do crescimento econômico" (FURTER, 1973, apud PAUVERT, 1960,p. 136), não devemos menosprezar sua relevância para a formação humana. Afinal, dependendo das medidas político-econômicas adotadas num determinado período, a educação escolar pode ser direcionada a somente reproduzir as ideias que o sistema vigente lhe impõe, negligenciando, assim, sua função primordial de oferecer ao educando as condições necessárias para uma formação 
integral e emancipadora. Por outro lado, a escola também pode suscitar contracorrentes críticas que a enxerguem não como uma simples programadora de máquinas falantes, mas como uma instituição a serviço de seres dotados de razão e de vontade, capazes de acolher ou rejeitar o que lhes é imposto ou proposto e possuidores de uma história pessoal única, de uma existência singular, permeada de uma intensa experiência educativa que ultrapassa os limites da educação escolar. Neste caso, seria o filosofar dispensável para educador e educando?

\subsection{INCÔMODO ATO DE FILOSOFAR}

Agora que chegamos ao terceiro e último termo essencial do tema desta Semana de Filosofia, convém dedicarmos algumas linhas para refletir sobre a afirmação kantiana de que não se pode ensinar filosofia, mas apenas ensinar a filosofar. Como sabemos, a filosofia não se confunde com a ciência, ainda que possa se debruçar criticamente sobre o método científico. Não se restringe à arte, embora possa fazer uso de vários gêneros literários para expressar ideias. Também não se reduz a simples visão de mundo, ainda que seja comum encontrar filósofos com diferentes pontos de vista sobre o mesmo assunto. De qualquer modo, querer ensinar filosofia sem desenvolver a atitude filosófica faz tanto sentido quanto querer ensinar natação sem a prática. 0 estímulo à inserção de metodologias ativas na educação parte do princípio de que só se aprende fazendo. Nesse sentido, podemos reformular a frase de Kant afirmando que só é viável ensinar ou aprender filosofia exercitando o ato de filosofar, isto é, pensando de modo abrangente e metódico.

É importante ressaltar que a atitude filosófica não é uma característica exclusiva de pensadores consagrados ou de especialistas com uma sólida formação acadêmica. Afinal, não foi a filosofia que deu origem ao filosofar, mas o filosofar, entendido como atividade reflexiva e crítica, que originou e alimenta a filosofia. Por isso, não é difícil entender porque Matthew Lipman criou e desenvolveu, nos EUA, em 1969, um programa denominado "Filosofia para Crianças". 
Segundo Lipman, transformar a sala de aula em uma comunidade de investigação seria ideal para se "fazer filosofia e não somente aprender uma lista de nomes e datas" (LIPMAN, 2001, p. 379). Com isso, a criança é introduzida no pensar filosófico, sem a preocupação de se tornar uma especialista em filosofia. Seguindo a mesma linha aqui no Brasil, Marcos AntonioLorieri justifica a iniciação filosófica de alunos da educação básica, lembrando que crianças e jovens também são pessoas e, de uma forma ou de outra, "põe-se questões próprias do âmbito da investigação filosófica; deparam-se e são envolvidos culturalmente com respostas a tais questões e têm o direito de ser iniciados no trato com elas e no processo de avaliação crítica das respostas" (LORIERI, 2002, p. 41).

Essa temática é pertinente ao momento atual em que os Estados brasileiros planejam a reformulação e implementação do currículo do ensino médio a partir da Base Nacional Comum Curricular. Este documento normativo teve duas versões antes desta que foi homologada em dezembro de 2018. Vejamos rapidamente como os termos filosofia e filosofar aparecem nas três versões da BNCC. Na versão de 2015, "filosofia" é citada 30 vezes, sendo 7 no plural e 23 no singular, enquanto "filosofar" aparece 4 vezes. Na versão de 2016, "filosofia" é citada 64 vezes, sendo 15 no plural e 49 no singular, enquanto "filosofar" aparece 2 vezes. Na versão homologada em 2018, "filosofia" é citada 26 vezes, sendo 20 no plural e 6 no singular, enquanto "filosofar" não aparece em parte alguma.

Ao expressar o termo "filosofia" no plural, as 3 versões da BNCC estão se referindo exclusivamente a "filosofias de vida", um conceito recorrente no desenvolvimento de um componente curricular do ensino fundamental denominado Ensino Religioso, que obviamente não é filosofia. Em relação ao termo "filosofar", que aparece apenas nas duas primeiras versões, seu sentido é o mesmo que trabalhamos neste artigo. Tanto que a versão de 2015 prescreve que, no ensino de Filosofia, "os processos de mediação docente podem variar desde que não se perca o protagonismo do/a estudante na oportunidade de filosofar" (BRASIL, 2015 , p. 295). Embora o texto de apresentação do componente curricular filosofia tenha sofrido algumas reformulações na versão de 2016, suas habilidades e objetivos previstos são praticamente os mesmos. 
Ao ingressar no ensino médio o aluno seria convidado e estimulado a "realizar a experiência do pensar filosófico". Ao final do 3ํano, deveria ser capaz de compreender "a abrangência, singularidade e importância da Filosofia na formação escolar básica e, por extensão, os possíveis lugares do filosofar na vida por vir" (BRASIL, 2016, p. 648).

A atual versão da BNCC, ao pensar a organização do ensino médio por área do conhecimento e não por componente curricular (apesar de manter a autonomia dos Estados na reformulação dos seus currículos), não permite a citação explícita do filosofar na educação básica. Mas, certamente, não pode evitar sua presença incômoda.

\section{CONSIDERAÇõES FINAIS}

Pensar de forma abrangente, radical e metódica não costuma ser uma ação prazerosa para qualquer um, pois nem sempre se encontram respostas satisfatórias para os problemas investigados ou, ainda que elas sejam encontradas, nem sempre são agradáveis ao indivíduo, ao grupo a que ele pertence ou a algum outro grupo social. Nesse sentido, a perspectiva de uma educação conservadora e reprodutora de ideias, valores, normas ou costumes "inquestionáveis" não pode permitir o desenvolvimento intencional do ato de filosofar. Caso contrário, as bases da própria estrutura social podem ser terrivelmente abaladas.

Já a concepção transformadora e emancipadora da educação não apenas estimula a reflexão crítica como se nutre dos produtos desta reflexão. De fato, a Filosofia da Educação deve "oferecer aos educadores um método de reflexão que lhes permita encarar os problemas educacionais, penetrando na sua complexidade e encaminhando a solução" de uma série de questões pertinentes à ação educativa (SAVIANI, 1996, p.23). Nessa perspectiva, não é possível nem concebível uma educação sem filosofar. 


\section{REFERÊNCIAS}

ABBAGNANO, Nicola. Dicionário de filosofia. Tradução da $1^{\underline{a} a}$ ed. brasileira coord. Alfredo Bosi. Revisão da trad. e trad. dos novos textos Ivone C. Benedetti. - 5. ed. São Paulo: Martins Fontes, 2007.

BRASIL.Base Nacional Comum Curricular. Brasília: MEC/Secretaria de Educação Básica, 2015.

.Base Nacional Comum Curricular .2 ${ }^{a}$ versão revista. Brasília: MEC/Secretaria de Educação Básica, 2016.

Base Nacional Comum Curricular. (Versão final). Brasília: MEC/Secretaria de Educação Básica, 2018.

Constituição da República Federativa do Brasil de 1988. Brasília, DF: Presidência da República.

Lei de Diretrizes e Bases da Educação Nacional. Lei no 9394/96, de 20 de dezembro de 1996.

DEWEY, John. Vida e educação. Tradução de Anísio S. Teixeira. São Paulo: Abril Cultural, 1980. (Coleção Os pensadores)

FURTER, Pierre. Educação e vida. 6. ed. Petrópolis: Vozes, 1973.

Educação e reflexão. 4. ed. Petrópolis: Vozes, 1971.

LIPMAN, Matthew.O pensar na educação. 3. ed. Tradução de Ann Mary Fighiera Perpétuo. Petrópolis: Vozes, 2001.

LORIERI, Marcos Antonio. Filosofia: fundamentos e métodos. São Paulo: Cortez, 2002.

SAVIANI, D. Educação: do senso comum à consciência filosófica. 11. ed. Campinas: Autores e associados, 1996.

Revista Páginas de Filosofia, v. 8, n. 1-2, p. 45-54, jan/dez. 2019 